\title{
Bronchopulmonary dysplasia: new becomes old again!
}

\author{
Colby L. Day ${ }^{1}$ and Rita M. Ryan ${ }^{1}$
}

Despite the many advances in neonatology, bronchopulmonary dysplasia (BPD) continues to be a frustrating disease of prematurity. BPD is a disease which is defined oddly by its treatment rather than its pathophysiology, leading to frequently changing nomenclature which has widespread implications on our ability to both understand and follow the progression of BPD. As various treatment modalities for BPD were developed and a larger number of extremely preterm infants survived, the "old" BPD based on lung injury from oxygen therapy and mechanical ventilation transitioned into a "new" BPD focused more on the interruption of normal development. However, the interruption of normal development does not solely apply to lung development. The effects of prematurity on vascular development cannot be overstated and pulmonary vascular disease has become the new frontier of BPD. As we begin to better understand the complex, multifactorial pathophysiology of BPD, it is necessary to again focus on appropriate, pathology-driven nomenclature that can effectively describe the multiple clinical phenotypes of BPD.

B ronchopulmonary dysplasia (BPD) has been a frustrating disease for neonatologists. Despite many other advances in neonatology, this is a disease for which we have made little progress. The primary risk factor, prematurity, is not in dispute and is quite consistent with the first report of BPD by a young Stanford radiologist (1). However, the changing definitions, as less mature infants survived, have made it difficult to deal with this disease, a disease defined oddly by its treatment (2). This has pulled us away from truly understanding BPD, causing us to focus on the epidemiology and nomenclature rather than the basic pathophysiology $(3,4)$. A recent NIH study group, Prematurity Respiratory Outcomes Program (PROP), is tackling both the semantics and the biology behind $\operatorname{BPD}(5,6)$.

To understand the epidemiology of BPD classifications and definitions, it is necessary to take a brief tour through the history of BPD. The term BPD was first coined in 1967 when Northway et al. outlined the previously undescribed sequelae of hyaline membrane disease/surfactant deficiency/respiratory distress syndrome (RDS) based upon a large group of preterm infants. BPD was described as a staged evolution of prolonged healing from RDS, compounded by oxygen toxicity and damage from positive pressure mechanical ventilation.
At that time, BPD was characterized as a chronic lung disease manifesting as cyanosis with an oxygen requirement clinically and radiologic changes on chest film (1). Based on this paper, over the next two decades, an oxygen requirement at $28 \mathrm{~d}$ of life became the main diagnostic criterion for BPD.

However, as larger numbers of very-low-birth-weight and extremely preterm infants began to survive, the clinical and radiologic progression of BPD was noted to be changing. In 1988 , a large follow-up study of 2 -y-old children with a history of a birth weight less than $1,500 \mathrm{~g}$ was performed and demonstrated that the requirement of oxygen therapy at $36 \mathrm{wk}$ postmenstrual age was a better predictor of abnormal pulmonary findings at $2 \mathrm{y}$ of age than an oxygen therapy requirement at $28 \mathrm{~d}$ of life (2). The previously accepted definition of BPD based on oxygen requirement at $28 \mathrm{~d}$ of life also appeared to be even less predictive in extremely preterm infants $(<30 \mathrm{wk}$ gestation at birth), who were surviving in greater numbers than ever before (2). This study did employ a very broad definition of "abnormal pulmonary findings" which likely resulted in the inclusion of a number of infants whose morbidities were not pulmonary-related in pathophysiology; however, the study is very notable for its introduction of a new classification system for BPD, utilizing the respiratory support required at $36 \mathrm{wk}$ postmenstrual age. Multiple methods of categorizing BPD were compared in the PROP study as mentioned previously. This multicenter observational prospective cohort study assessed over 700 infants at $36 \mathrm{wk}$ postmenstrual age and found a large degree of variation in assignment of BPD diagnoses. The study also noted that new clinical management strategies, for instance high flow nasal cannula, are not adequately accounted for in current definition strategies, leading to misclassification (5). And any good practicing neonatologist knows long before $36 \mathrm{wk}$ postmenstrual age whether a baby has $\mathrm{BPD}$, so the practical application of the term is also inconsistent. An agreed upon and appropriate method of nomenclature is necessary if we are to study BPD, try to understand BPD, and especially if we want to look at long-term outcomes. To do so, we need reliable methods to classify these infants easily and in a straightforward manner, so we can put them in the proper category to study associations later in childhood or even adulthood.

Although neonatologists began to care for surviving extremely preterm infants more frequently, the diagnosis of BPD remained one based upon treatment, namely the need 
for oxygen therapy and/or positive pressure/mechanical ventilation, rather than pathophysiology. This definition of BPD can be largely impacted by an individual clinician's judgment in regard to treatment and thus can lead to difficulties with standardized definitions of what it means to have BPD. More physiologic methods of characterizing BPD have been proposed but have not gained widespread use at this time (7). While neonatologists were likely correct that oxygen toxicity and barotrauma from prolonged mechanical ventilation were important exacerbations of recovery from RDS, leading to "old" BPD, mostly in infants born at $\geq 30$ wk gestation, the new population of extremely preterm infants born at $<30 \mathrm{wk}$ gestation introduced a new collection of possible pathophysiologic mechanisms (8). These infants who are born during the late canalicular and early saccular stage of normal lung development likely have pathology that exists independent of treatment modalities such as mechanical ventilation and oxygen. Most notably, the interruption of normal development by preterm birth would predictably result in aberrations in both alveolar and pulmonary vascular development. These aberrations in development have been the focus of a multitude of animal studies, most notably in preterm baboons and lambs (9-11), and have introduced the concept of a "new" BPD which is separate from the "old" BPD previously described, focused more on "growth arrest" rather than lung injury per se (3).

As the pathophysiology of BPD continued to be a focus of research, new techniques were developed to attempt to ameliorate RDS and subsequent BPD including antenatal glucocorticoids, gentler ventilation techniques, and surfactant administration. However, while these techniques certainly function to reduce further lung injury, they do not help with the prematurity-induced arrest of alveolar and pulmonary vasculature development that is seen in "new" BPD (12). Pathologic specimens of infants with BPD have demonstrated that routine surfactant treatment results in a reduction in the degree of fibrosis that was characteristic of "old" BPD, but does not prevent the arrest in lung development that is characteristic of "new" BPD (13).

But now, as neonatologists have begun to understand the impairment of pulmonary growth and development associated with the "new" BPD concept, this disease is morphing again (Figure 1). Our current neonatal intensive care units (NICUs) are starting to resemble our "old" NICUs with more babies still in the NICU at several months of age, being discussed as possible pediatric intensive care unit candidates (14). We are seeing an increase in infants requiring tracheostomies and home ventilation, presumably due to more frequent survival of the extremely low birth weight and medically complex infants, prompting studies evaluating the appropriate timing of tracheostomies (15). These trends are resulting in the need for more complex home care mechanisms, more specialist involvement, and an overall larger economic burden $(16,17)$.

The importance of the development of the vasculature of the lung cannot be overstated. It is clear that angiogenesis and lung development are intricately related (18). Vascular endothelial growth factor gene therapy increases survival, promotes

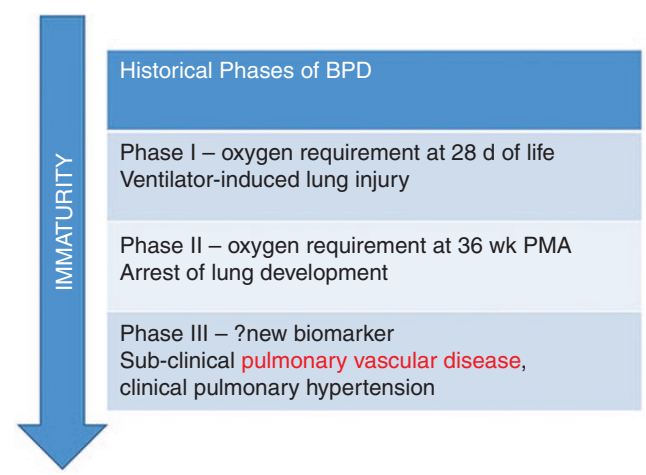

Figure 1. Historical phases of bronchopulmonary dysplasia (BPD). While prematurity remains a constant factor in the pathophysiology of $\mathrm{BPD}$, the disease itself has progressed from one defined by injury to one defined by impairment of lung development and now to one with additional pathophysiologic mechanisms including pulmonary vascular disease.

lung angiogenesis, and prevents alveolar damage in hyperoxiainduced lung injury, providing evidence of the link between angiogenesis and alveolarization (19). Now, once again, BPD is transforming into a disease characterized by a different pathophysiology, prompting the need for research into which insults negatively impact the vasculature of the lung. In human infants who died with "old" BPD, there is near absence of normal vasculature $(20,21)$. The fetal lung in utero develops in a very hypoxic environment and when an infant is delivered prematurely, the development of the premature neonatal lung begins to occur in what is a relatively hyperoxic environment, causing problems heretofore not well described. We do know that hyperoxia negatively impacts lung vasculature by mechanisms such as suppression of vascular endothelial growth factor and induction of angiopoietin 2, among others (22-24). Additionally, other contributing factors inherent to the development of BPD such as prematurity and mechanical ventilation appear to lead to further lung damage and impaired development through mechanisms such as induction of regulators of angiogenesis such as endoglin (CD105) and matrix metalloproteinase $9(25,26)$. However, preterm baboons that were not exposed to hyperoxia and were supported with gentle ventilation strategies still had evidence of arrested alveolar and pulmonary vasculature development, indicating that mechanical ventilation and oxygen therapy are not the only contributors to this vasculature growth impairment (11).

This relatively new clinical concept of neonatal pulmonary vascular disease (PVD) is becoming more and more common, and can manifest in a multitude of ways including impaired gas exchange, intolerance of exertion, or altered pulmonary blood flow in the setting of acute respiratory infections to name a few (27). The most severe form of PVD occurs in babies with BPD who develop frank pulmonary hypertension. The risk for pulmonary hypertension in these infants with BPD is $18-25 \%$ based on two studies from Korea and Alabama, compiled nicely in an excellent review (27-29). Pulmonary hypertension is known to contribute significantly to morbidity and mortality in older BPD patients; however, limitations in methods of 


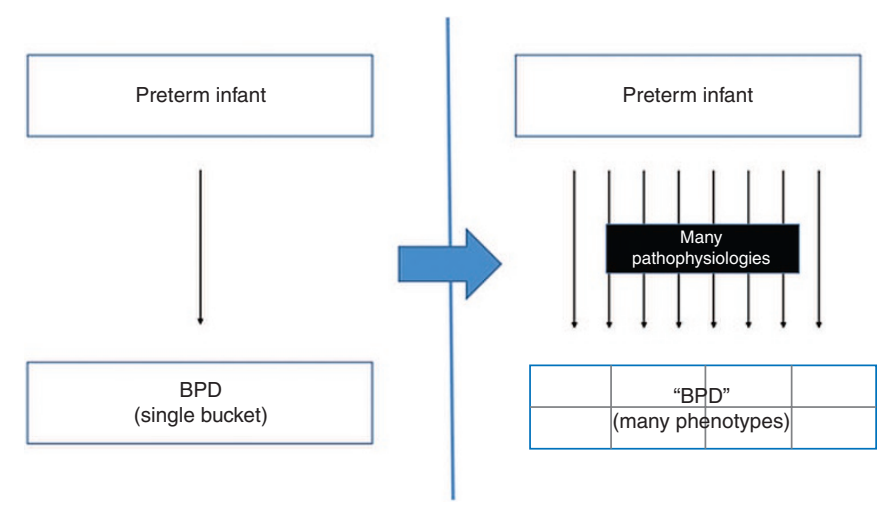

Figure 2. Pathophysiologies of bronchopulmonary dysplasia (BPD). As we improve our clinical phenotyping of infants with BPD, we should also improve our understanding of the different pathophysiologies leading to BPD and simultaneously develop a nomenclature system that is pathologydriven (e.g., BPD-poor respiratory control type, etc.).

diagnosing and quantifying PVD and pulmonary hypertension represent a definite challenge, especially in those infants who may have "subclinical" PVD. As pulmonary hypertension is being diagnosed more frequently, more therapies such as sildenafil are being used in babies with BPD at 3-4 mo of age $(30,31)$, with an especially increased use of sildenafil in the least mature infants, those with more severe BPD, and those who are small for gestational age. There also continues to be wide variation in clinical practice in terms of frequency and duration of sildenafil exposure for these infants (32). This is a significant problem that needs further attention, specifically with a further focus on the pathophysiology of PVD and pulmonary hypertension; so, we can better understand and treat these babies.

What happens to the fetus, and logically also to a baby in the NICU during what would have been his or her third trimester, has important effects on later overall health and development. For example, simple hyperoxia exposure in the neonatal rodent results in adverse effects on the heart, kidney, and lungs, as well as deficits in spatial and recognition memory (33-38). The type of mechanical ventilation utilized in preterm sheep influences not only lung development, but also affects brain function later in life $(39,40)$. As a result, the new horizon of BPD research must incorporate studies looking into much broader and long-term effects of neonatal respiratory care. However, these long-term effects cannot be limited to pulmonary disease alone. In order to understand and hopefully alter the course of BPD, which we now know has lifelong impacts on virtually every body system, we must adequately define nomenclature and classification. A simple biomarker during the neonatal period or a simple and physiologically relevant BPD classification will improve our abilities to implement both retrospective and prospective studies. This is a topic that is discussed and debated among neonatologists and pediatric pulmonologists and we need to continue these important discussions. What clinical study groups are now understanding is that although babies with BPD may look similar at first glance, they actually are quite heterogeneous, requiring sorting into more categories than previously thought and likely arriving to a diagnosis of BPD through various pathophysiologies. More rigors in understanding the pathophysiology with the purpose of then assigning a BPD category might help us partition babies earlier in the NICU course to different prevention/treatment pathways. One prevention or treatment strategy is unlikely to be a "one size fits all" remedy. These BPD categories essentially would function as clinical phenotypes to help describe what pathophysiologic pathway a baby took to arrive at the final diagnosis of BPD (Figure 2). Examples of BPD categories could include in utero inflammation, maternal pre-eclampsia, immature respiratory control, genetic predisposition, chest wall instability, pulmonary vascular disease, oxygen toxicity, postnatal infection or sepsis, and mechanical ventilation. And as our understanding of BPD and its etiologies increases, more categories may need to be created to include the input from important contributors such as genetic predispositions and biomarkers.

In summary, the disease of $\mathrm{BPD}$, or chronic respiratory disease of the preterm neonate, has evolved over time, as the lower limit of surviving infants has moved to earlier and earlier gestational ages and our NICU care has changed. As we learn more about the fundamental impairment of developing vasculature in infants who are born prematurely and exposed to hyperoxia and mechanical ventilation, the new biological frontier involves understanding the underlying, significant PVD and devising treatments to support normal vascular development of the lung. An additional challenge is to understand the ramifications of the entire NICU experience on a growing, premature infant's future as an adult, which requires long-term and costly follow up. And finally, as we continue to improve and standardize our clinical phenotyping of babies with BPD, with an eye to pathophysiology, genetic and other biomarker studies will become more meaningful.

\section{STATEMENT OF FINANCIAL SUPPORT}

There are no financial disclosures.

Disclosure: The authors have no conflicts of interest to disclose.

\section{REFERENCES}

1. Northway WH Jr, Rosan RC, Porter DY. Pulmonary disease following respirator therapy of hyaline-membrane disease. Bronchopulmonary dysplasia. N Engl J Med 1967;276:357-68. 
2. Shennan AT, Dunn MS, Ohlsson A, Lennox K, Hoskins EM. Abnormal pulmonary outcomes in premature infants: prediction from oxygen requirement in the neonatal period. Pediatrics 1988;82:527-32.

3. Jobe AJ. The new BPD: an arrest of lung development. Pediatr Res 1999;46: 641-3.

4. Ryan RM. A new look at bronchopulmonary dysplasia classification. J Perinatol 2006;26:207-9.

5. Poindexter BB, Feng R, Schmidt B, et al.; Prematurity and Respiratory Outcomes Program. Comparisons and limitations of current definitions of bronchopulmonary dysplasia for the prematurity and respiratory outcomes Program. Ann Am Thorac Soc 2015;12:1822-30.

6. Pryhuber GS, Maitre NL, Ballard RA, et al.; Prematurity and Respiratory Outcomes Program Investigators. Prematurity and respiratory outcomes program (PROP): study protocol of a prospective multicenter study of respiratory outcomes of preterm infants in the United States. BMC Pediatr 2015;15:37.

7. Walsh MC, Wilson-Costello D, Zadell A, Newman N, Fanaroff A. Safety, reliability, and validity of a physiologic definition of bronchopulmonary dysplasia. J Perinatol 2003;23:451-6.

8. Jobe AH, Bancalari E. Bronchopulmonary dysplasia. Am J Respir Crit Care Med 2001;163:1723-9.

9. Coalson JJ, Winter V, deLemos RA. Decreased alveolarization in baboon survivors with bronchopulmonary dysplasia. Am J Respir Crit Care Med 1995;152:640-6.

10. Albertine $\mathrm{KH}$, Jones GP, Starcher BC, et al. Chronic lung injury in preterm lambs. Disordered respiratory tract development. Am J Respir Crit Care Med 1999;159:945-58.

11. Coalson JJ, Winter VT, Siler-Khodr T, Yoder BA. Neonatal chronic lung disease in extremely immature baboons. Am J Respir Crit Care Med 1999;160:1333-46.

12. Coalson JJ. Pathology of bronchopulmonary dysplasia. Semin Perinatol 2006;30:179-84.

13. Husain AN, Siddiqui NH, Stocker JT. Pathology of arrested acinar development in postsurfactant bronchopulmonary dysplasia. Hum Pathol 1998:29:710-7.

14. Guaman MC, Gien J, Baker CD, Zhang H, Austin ED, Collaco JM. Point prevalence, clinical characteristics, and treatment variation for infants with severe bronchopulmonary dysplasia. Am J Perinatol 2015;32:960-7.

15. Rane S, Bathula S, Thomas RL, Natarajan G. Outcomes of tracheostomy in the neonatal intensive care unit: is there an optimal time? J Matern Fetal Neonatal Med 2014;27:1257-61.

16. Petrou S, Eddama O, Mangham L. A structured review of the recent literature on the economic consequences of preterm birth. Arch Dis Child Fetal Neonatal Ed 2011;96:F225-32.

17. Petrou S, Mehta Z, Hockley C, Cook-Mozaffari P, Henderson J, Goldacre $M$. The impact of preterm birth on hospital inpatient admissions and costs during the first 5 years of life. Pediatrics 2003;112(6 Pt 1):1290-7.

18. Jakkula M, Le Cras TD, Gebb S, et al. Inhibition of angiogenesis decreases alveolarization in the developing rat lung. Am J Physiol Lung Cell Mol Physiol 2000;279:L600-7.

19. Thebaud B, Ladha F, Michelakis ED, Sawicka M, Thurston G, Eaton F, et al. Vascular endothelial growth factor gene therapy increases survival, promotes lung angiogenesis, and prevents alveolar damage in hyperoxiainduced lung injury: evidence that angiogenesis participates in alveolarization. Circulation 2005;112:2477-86.

20. Bhatt AJ, Pryhuber GS, Huyck H, Watkins RH, Metlay LA, Maniscalco WM. Disrupted pulmonary vasculature and decreased vascular endothelial growth factor, Flt-1, and TIE-2 in human infants dying with bronchopulmonary dysplasia. Am J Respir Crit Care Med 2001;164(10 Pt 1):1971-80.
21. Maniscalco WM, Watkins RH, Pryhuber GS, Bhatt A, Shea C, Huyck H. Angiogenic factors and alveolar vasculature: development and alterations by injury in very premature baboons. Am J Physiol Lung Cell Mol Physiol 2002;282:L811-23.

22. Maniscalco WM, Watkins RH, D’Angio CT, Ryan RM. Hyperoxic injury decreases alveolar epithelial cell expression of vascular endothelial growth factor (VEGF) in neonatal rabbit lung. Am J Respir Cell Mol Biol 1997;16: $557-67$.

23. Bhandari V, Choo-Wing R, Lee CG, et al. Hyperoxia causes angiopoietin 2-mediated acute lung injury and necrotic cell death. Nat Med 2006;12:1286-93.

24. Thomas W, Seidenspinner S, Kramer BW, et al. Airway angiopoietin-2 in ventilated very preterm infants: association with prenatal factors and neonatal outcome. Pediatr Pulmonol 2011;46:777-84.

25. De Paepe ME, Patel C, Tsai A, Gundavarapu S, Mao Q. Endoglin (CD105) up-regulation in pulmonary microvasculature of ventilated preterm infants. Am J Respir Crit Care Med 2008;178:180-7.

26. Harijith A, Choo-Wing R, Cataltepe S, et al. A role for matrix metalloproteinase 9 in IFN $\gamma$-mediated injury in developing lungs: relevance to bronchopulmonary dysplasia. Am J Respir Cell Mol Biol 2011;44:621-30.

27. Mourani PM, Abman SH. Pulmonary vascular disease in bronchopulmonary dysplasia: pulmonary hypertension and beyond. Curr Opin Pediatr 2013;25:329-37.

28. An HS, Bae EJ, Kim GB, et al. Pulmonary hypertension in preterm infants with bronchopulmonary dysplasia. Korean Circ J 2010;40:131-6.

29. Bhat R, Salas AA, Foster C, Carlo WA, Ambalavanan N. Prospective analysis of pulmonary hypertension in extremely low birth weight infants. Pediatrics 2012;129:e682-9.

30. Mourani PM, Sontag MK, Ivy DD, Abman SH. Effects of long-term sildenafil treatment for pulmonary hypertension in infants with chronic lung disease. J Pediatr 2009;154:379-84, 384.e1-2.

31. Nyp M, Sandritter T, Poppinga N, Simon C, Truog WE. Sildenafil citrate, bronchopulmonary dysplasia and disordered pulmonary gas exchange: any benefits? J Perinatol 2012;32:64-9.

32. Backes CH, Reagan PB, Smith CV, Jadcherla SR, Slaughter JL. Sildenafil Treatment of Infants With Bronchopulmonary Dysplasia-Associated Pulmonary Hypertension. Hosp Pediatr 2016;6:27-33.

33. Ramani M, Bradley WE, Dell'Italia LJ, Ambalavanan N. Early exposure to hyperoxia or hypoxia adversely impacts cardiopulmonary development. Am J Respir Cell Mol Biol 2015;52:594-602.

34. Ramani M, van Groen T, Kadish I, Bulger A, Ambalavanan N. Neurodevelopmental impairment following neonatal hyperoxia in the mouse. Neurobiol Dis 2013;50:69-75.

35. Jiang JS, Chou HC, Yeh TF, Chen CM. Neonatal Hyperoxia Exposure Induces Kidney Fibrosis in Rats. Pediatr Neonatol 2015;56:235-41.

36. Torbati D, Tan GH, Smith S, et al. Multiple-organ effect of normobaric hyperoxia in neonatal rats. J Crit Care 2006;21:85-93; discussion 93-4.

37. Vento M, Sastre J, Asensi MA, Viña J. Room-air resuscitation causes less damage to heart and kidney than 100\% oxygen. Am J Respir Crit Care Med 2005; 172:1393-8.

38. Kumar VH, Lakshminrusimha S, Kishkurno S, et al. Neonatal hyperoxia increases airway reactivity and inflammation in adult mice. Pediatr Pulmonol 2016; e-pub ahead of print 26 April 2016.

39. Rehan VK, Fong J, Lee R, et al. Mechanism of reduced lung injury by highfrequency nasal ventilation in a preterm lamb model of neonatal chronic lung disease. Pediatr Res 2011;70:462-6.

40. Albertine $\mathrm{KH}$. Brain injury in chronically ventilated preterm neonates: collateral damage related to ventilation strategy. Clin Perinatol 2012;39: $727-40$. 